\title{
CAPTURAS DO SENTIR: DISPOSITIVOS ACERCA DA SENSIBILIDADE ANIMAL ENTRE A CIÊNCIA E O DIREITO'
}

\section{Capturing senses: Dispositifs about the animal sensibility between the science and the right}

\section{Jorge Scola}

Mestre em Antropologia Social (2017) e Bacharel em Ciências Sociais pela Universidade Federal do Rio Grande do Sul (UFRGS, 2015). Atualmente, cursa o Doutorado em Antropologia Social pelo Programa de Pós-Graduação da mesma instituição. ID ORCID: https://orcid.org/0000-0001-6502-0326.

\section{Resumo}

Partindo da recepção e divulgação do Manifesto de Cambridge, discuto a multiplicidade de atuações (MOL, 2007) das noções de senciência, sensibilidade e consciência a partir da alocação do dispositivo no código civil francês "em nome da sensibilidade dos animais". Em seguida, discuto as noções de "bem comum", "responsabilidade" e "felicidade" utilizadas por certos agentes em seus discursos a respeito da senciência e da sensibilidade. Nestas formas de produzir moralmente o mundo (FASSIN, 2012) identifico a promoção de novos imperativos morais ancorados em discursos emotivos sobre a apercepção transespécie da capacidade de sentir. Trata-se, assim, de um esforço interpretativo que objetiva tensionar as questões trazidas por meio de uma interseção dos debates da antropologia moral e antropologia das emoções para a discussão do campo das relações humano-animal e dos estudos em ciência e tecnologia.

Palavras-chave: Bem Comum, Direitos dos Animais, Senciência, Tecnologias de Governo.

\section{Abstract}

From the starting point of the reception and dissemination of the Cambridge Manifesto, this paper aims to discuss the multiplicity of enactings (MOL, 2007) of the notions of sentience, sensitivity and consciousness from the appropriation of a device in the French civil code: "on the behalf of the sensitivity of animals". After, I discuss the notions of "common good", "responsibility" and "happiness" used by certain agents in their speeches about the sentience and sensitivity. In these ways

Uma primeira versão deste texto foi debatida em ocasião da reunião do grupo de pesquisa Espelho Animal (PPGAS/UFRGS). Agradeço pela leitura e comentários dos presentes, especialmente dos professores Bernardo Lewgoy e Jean Segata. Também pude amadurecer essas reflexões no âmbito da disciplina Antropologia das Emoções, ministrada por Ceres Víctora no PPGAS/UFRGS, em 2017, a quem também agradeço pelas sugestões e estímulos. Izabella Bosisio e Mariana Picolotto também foram leitoras generosas e pacientes e me auxiliaram a perceber possibilidades de aprimoramento na redação de alguns argumentos. 
of producing the world morally (FASSIN, 2012) I identify a promotion of new moral imperatives anchored in emotional speeches about the identification of trans-species ability to feel. Thus, it is an interpretive effort that focus on the tendencies brought by an intersection of discussions from moral anthropology and anthropology of emotions to a debate of the relationship human-animal field and the studies in science and technology.

Keywords: Animal Rights, “Common Good”, Sentience, Technologies Of Government.

\section{INTRODUÇÃO: CAPTURAS DO “SENTIR”?}

Um conjunto de questões e tensionamentos pode ser apontado na produção de vínculos entre a produção de prescrições morais e a nossa habilidade de agir e reagir diante de "descobertas científicas". Este texto volta-se à veiculação do "Manifesto de Cambridge", publicação produto de pesquisas neurocientíficas a respeito da capacidade de sentir e de ter a consciência desse potencial por animais não humanos e à alocação do reconhecimento da "sensibilidade" destes pela revisão do Parlamento francês ao Código Civil. Nas bordas desse processo identifico o trabalho público de uma organização "animalitária" (como para Digard (1999)) e a ascensão da frente discursiva pró-reconhecimento do caráter "dotado de sensibilidade" dos animais. O próprio trânsito de categorias (da "senciência" identificada por neurocientistas à "sensibilidade" sobre a qual se legisla) aponta para a centralidade da "sensibilidade" e sua potência em articular distintos âmbitos. O limite entre a autoevidência da noção de sensibilidade e suas consequências em situar distintos processos sob um mesmo horizonte ético no Ocidente é trazida por Duarte (1999), para quem:

Todo mundo sabe mais ou menos o que é sensibilidade, e bem se pode reconhecer que continuam convivendo entre nós a acepção "fisiológica" e a acepção "sentimental" da categoria. Porém esta última acepção certamente é mais englobante, fazendo supor que seja natural imaginar as afecções do espírito como ao mesmo tempo dependentes e autônomas do substrato nervoso (DUARTE, 1999, p. 26).

\footnotetext{
Como uma transposição para o universo dos animais das injunções relacionadas ao humanitarismo como forma de governo e seus imperativos morais. Sobre a discussão, ver as etnografias recentes de Pinto (2016) e Lewgoy, Sordi e Pinto (2016).
} 
Tal sobreposição entre o "fisiológico" e o "sentimental", como veremos, é continuamente trazida à tona de diferentes formas, seja pelos neurocientistas de Cambridge, seja pela proposição francesa. Quando agentes da neurociência procuram pela "capacidade de sentir" ou pela "busca do sentido de si mesmo" nos animais, esses atores parecem inclusive aprofundar a ênfase essencialista, uma vez que estão investigando não somente o que é o "sentir humano" mas as próprias capacidades de sentir "nelas mesmas", numa inscrição profundamente materialista da realidade, na qual a sensibilidade é um dado do mundo biológico ou neurológico.

Neste sentido, a busca pelo que define exatamente a capacidade de sentir parece apontar para o caráter regulatório da senciência. Por conseguinte, não agirmos em conformidade com essa identificada capacidade de sentir alheia pode ser algo enquadrado como o fomento de um ato contra o "bem-estar" e "a felicidade" de outros seres. Trata-se de uma ação que se constitui contra uma prescrição moral, fortemente amparada no repertório da ciência moderna.

Meu interesse aqui é o de localizar a agência específica dessas categorias (sensibilidade e senciência) junto a agentes públicos na conformação de novos imperativos morais e seus efeitos políticos. A maneira como tais prescrições trazem formas de articular responsabilização e novas subjetivações pela parte de quem reconhece a sensibilidade alheia poderá ser percebida em dados relacionados à replicação e divulgação científica relativa ao Manifesto de Cambridge. Tudo isso joga luz no caráter moral das categorias - "moral" aqui identificada como a habilidade de diferentes agentes construírem uma ideia de "bem" (FASSIN, 2012) ${ }^{3}$.

Assumindo os efeitos públicos de replicação do Manifesto e da reforma legal francesa como dispositivos ${ }^{4}$ (AGAMBEN, 2009, 2014), intento salientar

\footnotetext{
3 Na proposta de Fassin (2012), “[...] as questões morais estão imbricadas na substância do social; [...] A antropologia moral lida com o modo como questões morais são colocadas e endereçadas, ou, simetricamente, como questões não morais são reconfiguradas como morais. Ela explora como as categorias morais pelas quais nós apreendemos o mundo e identificamos as comunidades morais que construímos, examina as significações morais das ações e o trabalho moral dos agentes [...]. O objeto da antropologia moral é a produção moral do mundo" (FASSIN, 2012 apud SCHUCH, 2014, p. 104).

4 Para o filósofo Giorgio Agamben, os dispositivos capturam os viventes, dando lugar a processos de subjetivação e dessubjetivação. Nos termos do autor, um dispositivo corresponde a "qualquer coisa que tenha de algum modo a capacidade de capturar, orientar, determinar, interceptar, modelar, controlar e assegurar os gestos, as condutas, as opiniões e os discursos dos seres viventes" (AGAMBEN, 2009, p.40).
} 
a dimensão de tecnologia de governo que estes ganham na qualidade de forma de governar a vida dos "seres viventes" por meio da captura 5 .

O texto está dividido em três seções. Na primeira parte, apresento o contexto de formulação da mudança do código civil francês a ponto de reconhecer o caráter sensível dos animais e os meios pelos quais essa mudança é valorada pelos políticos designados para o caso, até a proposta sagrar-se vencedora. A segunda seção do texto está voltada para as atenções envolvidas no debate acerca das capacidades de sensibilidade e da consciência animal abordadas por neurocientistas, tomando como centro dessa rede o Manifesto de Cambridge, publicado em junho de 2012. Aqui, focalizo especialmente as formas pelas quais múltiplas "consciências" são atuadas (no sentido de Mol (2007)) e, principalmente, como consciência, senciência e sensibilidade (embora sem dúvida designem "processos" distintos) podem ser associadas segundo um importante trabalho de mediação (LATOUR, 1994) movido por diferentes agentes.

Na terceira parte, discorro sobre como as noções de humanidade e animalidade são acionadas nos debates analisados. Argumento que a aproximação interespecífica aqui atuada parece estar reificando uma matriz de legibilidade que faz usos de argumentos "gradualistas" a respeito da condição de humanidade e cujo ápice está na identificação de faculdades de interioridade tidas como privilégios da mente humana, as quais se tornam aplicáveis aos animais segundo uma forma de torná-los um próximo bastante localizado. Por fim, pretendo rastrear as implicações propriamente morais na agenda da senciência, de modo a visibilizar suas localizações sobre os temas do reconhecimento, da responsabilização, do bem comum e da felicidade.

\section{EM NOME DA SENSIBILIDADE ANIMAL E DE SUA SENCIÊNCIA: UMA NOVA FRENTE DISCURSIVA}

O movimento de reformas em legislações a respeito do estatuto do animal viveu um incremento de contornos importantes em relativamente pouco

\footnotetext{
As preocupações biopolíticas dessa análise, conforme as entendo, convergem com as proposições de Butler (2015), na forma como esta enfatiza o caráter contingente e localizado dos efeitos políticos atinentes ao que designa como "enquadramentos" como dispositivos de regulação da comoção pública. O enquadramento vale-se da circulação controlada de imagens e representações, e eu gostaria de entender o Manifesto de Cambridge como um destes, de modo a salientar como a comoção é dependente de "apoios sociais para o sentir" (BUTLER, 2015, p. 81) e como o percurso de replicação das suas conclusões acirra a coprodução de um dado "circuito de comoção social”, longe do qual não poderíamos experimentar sentir comoção e reivindicá-la como nossa (Ibidem, p. 82).
} 
tempo. Em publicação de 2011, Ciméa Barbato Bevilacqua apresentou, por meio da análise de decisões judiciais de pleitos de direitos para chimpanzés, importantes apontamentos para a compreensão das mudanças em curso e das formas de acolhimento dos animais em regimes legais. Grande parte dos argumentos científicos analisados para a concessão de direitos "fundamentais" como a liberdade, na forma de um habeas corpus, era calcada na "impressionante similaridade do DNA de seres humanos e grandes primatas não humanos" (BEVILACQUA, 2011, p. 91).

Uma das mais replicadas manchetes por jornais e páginas relacionadas à promoção dos direitos dos animais durante o ano de 2015, a alteração no código civil da França a respeito da figura jurídica que acolhe o animal, foi em geral recebida como uma "decisão histórica". Tal acepção faz sentido tanto pelo fato de que o Código Civil vigente datava de 1804, no Império Napoleônico - donde vem o contexto de sua redação, que previa a figura jurídica do animal como um bem móvel, em especial com vistas ao seu uso para o trabalho e para o transporte ${ }^{6}$-, quanto pela capacidade que têm o debate e a "mudança em nome do reconhecimento dos animais" de influenciar outros países na mesma direção.

Produto de uma trajetória bastante própria, a releitura da legislação vigente foi uma iniciativa de uma organização não governamental, a Fondation 30 Millions d'Amis, a qual postula em seu site na internet como uma de suas causas (combats) o reconhecimento dos animais como seres sensíveis por meio de mudanças no status jurídico que lhes é outorgado ${ }^{7}$. Esta proposição, que seria posteriormente a Lei no 2015-177, aprovada em fevereiro de 2015 após passar pelo trâmite no Senado francês, parece ter encontrado um caminho jurídico pavimentado a partir do caso da orangotango Sandra, que

\footnotetext{
Artigo 528 do Código Civil francês em vigor até 2015: "Sont meubles par leur nature les animaux et les corps qui peuvent se transporter d'un lieu à un autre, soit qu'ils se meuvent par eux-mêmes, soit qu'ils ne puissent changer de place que par l'effet d'une force étrangère" (FRANÇA, 1804).

7 Ver: FONDATION 30 MILLIONS D’AMIS. Statut juridique : de nouveaux espoirs pour (tous) les animaux. In: FONDATION 30 MILLIONS D’AMIS. La fondation. Nos combats. Paris: Fondation 30 Millions d'Amis, [2017]. Disponível em: http://www.30millionsdamis.fr/la-fondation/nos-combats/ exiger-un-statut-juridique-de-lanimal. Acesso em: jan. 2016.
} 
ganhara o estatuto de "pessoa não humana" após decisão da Suprema Corte de Justiça da Argentina ${ }^{8}$.

Se a "orangotango Sandra" ganhara o estatuto de pessoa não humana por uma decisão judicial atinente apenas à sua própria liberdade - isto é, fora lida pelo Estado como um indivíduo, numa operação de judicialização da política, já que sua causa era única -, o que a reforma da legislação do código civil francês realiza parece ser um efeito de ordem muito mais abrangente. Trata-se, como quer a organização que chega a impetrar o pedido de mudança, do reconhecimento dos animais no ordenamento jurídico daquele país, por meio, também, do reconhecimento da sua capacidade sensível. Chamo atenção para o fato de que estamos diante de dispositivos de abrangências generalistas (isto é, em nome de todos os animais, sem denominações ou privilégios) e que isso é importante, uma vez que ultrapassa, em certa medida, os argumentos "em nome da natureza" que costumam vigorar na prática de proteção "ecológica”, que pleiteiam o "manejo correto" pelos humanos de espécies categorizadas como "exóticas" ou "em extinção".

8 Em sentença inédita até então, a Câmara de Cassação Penal de Buenos Aires decidiu, no final de 2014, que, embora a "orangotango Sandra" não seja um ser humano, ela tem sentimentos e, por isso, a ela se pode aplicar um habeas corpus, para que possa viver com mais liberdade, após uma ação interposta pela Associação de Funcionários e Defensores dos Direitos dos Animais (AFADA). Sandra vivia num zoológico argentino desde 1994, aonde chegou após nascer na Alemanha. Juridicamente, o amparo do caso deu-se baseado numa situação de "confinamento injustificado de um animal com provada capacidade cognitiva". Na imprensa argentina, Sandra ficou conhecida como a "orangotango triste". Sobre o caso, ver, entre outras replicações:

G1. Tribunal argentino deve decidir destino de orangotango 'triste' de zoo. In: G1. Natureza. 28 mai. 2015. Disponível em: http://g1.globo.com/natureza/noticia/2015/05/tribunal-argentino-deve-decidir-destino-de-orangotango-triste-de-zoo.html. Acesso em: jul. 2017;

AFP. Agence France Presse. Sandra, a orangotango, vira celebridade da luta pelos direitos dos animais. In: ESTADO DE MINAS. Internacional. 22 dez. 2014. Disponível em: https://www.em.com.br/app/ noticia/internacional/2014/12/22/interna_internacional,601840/sandra-a-orangotango-vira-celebridade-da-luta-pelos-direitos-dos-animais.shtml. Acesso em: jul. 2017;

GAUCHAZH. Orangotango Sandra, pessoa "não humana" na Argentina, ganha lar no Brasil. In: GAUCHAZH. Geral. 01 out. 2015. Disponível em: https://gauchazh.clicrbs.com.br/geral/noticia/2015/10/ orangotango-sandra-pessoa-nao-humana-na-argentina-ganha-lar-no-brasil-4860599.html. Acesso em: jul. 2017.

9 Ou, ainda, para o caso francês propriamente, se trata de uma inflexão sobre o estatuto do animal como um "direito positivo" no modelo da reforma da legislação vigente. Não era o caso, por exemplo, de um projeto de lei acerca dos "animais perigosos", que regulamentava pela restrição à circulação de pitbulls por meio de sua essencialização como "agressivos", no final dos anos 1990 (Projet de loi relatif aux animaux dangeroux et errants, et à la protection de les animaux, No. 249/1998). Ver na íntegra em: FRANÇA. SÉNAT. Projet de loi relatif aux animaux dangereux et errants, et à la protection des animaux. In: SÉNAT. Travaux parlementaires.[1998]. Disponível em: http://www.senat.fr/rap/l97-429/197-4294. html. Acesso em: jul. 2017. 
Com o objetivo de "modernizar e simplificar" a legislação vigente e os procedimentos nas áreas de Justiça e assuntos internos, a reforma propunha a mudança de redação do trecho citado do Código Civil francês nos seguintes termos ${ }^{10}$ :

Le code civil est ainsi modifié:

$1^{\circ}$ Avant le titre Ier du livre II, il est inséré un article 515-14 ainsi rédigé :

"Art. 515-14. - Les animaux sont des êtres vivants doués de sensibilité. Sous réserve des lois qui les protègent, les animaux sont soumis au régime des biens. »; (...)

$4^{\circ} L^{\prime}$ article 528 est ainsi rédigé :

«Art. 528. - Sont meubles par leur nature les biens qui peuvent se transporter d'un lieu à un autre. ";

$5^{\circ}$ A l'article 533, le mot: "chevaux, " est supprimé;

$6^{\circ}$ A l'article 564, les mots: «ces objets » sont remplacés par les mots:

"ces derniers";

$7^{\circ}$ Au premier alinéa de l'article 2500, la référence : « 516 » est remplacée par la référence : "515-14»;

$8^{\circ}$ A l'article 2501, la référence: "du neuvième alinéa » est supprimée et, après le mot: "sont ", sont insérés les mots : "soumis au régime des »(FRANÇA, 2015a).

O grande destaque dessa proposição, porém, é o reconhecimento dos animais como seres vivos dotados de sensibilidade ${ }^{11}$. O relator designado pelo Senado, M. Thani Mohamed Soilihi, avaliando a questão proposta, apresenta uma posição muito representativa a respeito do "reconhecimento da senciência animal":

${ }^{10}$ Na íntegra em: FRANÇA. Loi nº 2015-177 du 16 février 2015. Relative à la modernisation et à la simplification du droit et des procédures dans les domaines de la justice et des affaires intérieures (1) - Article 2. In: LEGIFRANCE. Accueil. Les autres textes législatifs et réglementaires. [2015a]. Disponível em: http://www.legifrance.gouv.fr/eli/loi/2015/2/16/2015-177/jo/article_2. Acesso em: jul. 2017.

${ }^{11}$ A iniciativa que dá origem à reforma legislativa aqui analisada é, na verdade, uma entre os "mais de quinze pedidos de habilitação de modernização de simplificação e modernização da legislação”. As fontes dessas discussões encontram-se nos registros do próprio site do Senado francês:

FRANÇA. SÉNAT. Comptes Rendus de la Commission des Lois. Travaux parlementaires. 14 jan. 2015. [2015b]. Disponível em: http://www.senat.fr/compte-rendu-commissions/20150112/lois.html. Acesso em: jul. 2017. 
[...] Algumas destas novas disposições têm uma ligação tênue com o texto original: é o caso relativo ao estatuto dos animais. Por que legislar apressadamente sobre tal assunto? A formulação escolhida, longe de ser perfeita, levanta questões reais. Seus defensores acreditam que deve haver um reconhecimento simbólico da especificidade dos animais no Código Civil. Isso levanta sérias questões de princípio: um ato nomeadamente simbólico ou é realmente normativo? O Código Civil deveria ser um código simbólico? Proponho, por todas estas razões, suprimir esta disposição. Quanto aos outros, proponho manter as soluções anteriormente aprovadas pelo Senado, em particular as garantias adicionais que nós discutimos ${ }^{12}$. (FRANÇA, 2015b) (tradução minha).

Ao problematizar o movimento de reconhecimento identificado como meramente simbólico, o relator procura rastrear as "consequências práticas" que tal concessão operaria, recomendando cautela e maior debate, uma vez que seria difícil avaliar o impacto real dessa lei. A partir daí são expostos posicionamentos de nove senadores presentes na comissão de julgamento do projeto, além do relator. Um deles, por exemplo, não concorda com a despolitização da questão, ao propor uma aproximação entre simbólico e jurídico, salientando que "o impacto simbólico de uma lei não é necessariamente zero" $^{13}$ (FRANÇA, 2015b).

Consta o registro de outro dos avaliadores do projeto na concordância com o relator: "Concordo com o relator: nós amamos todos os animais, mas quanto ao procedimento, a introdução desta disposição é inaceitável. Suas consequências econômicas também poderiam ser bastante desastrosas"

\footnotetext{
${ }_{12}$ No original: "Certaines de ces dispositions nouvelles ont un lien ténu avec le texte initial : c'est le cas de celle relative au statut des animaux. Pourquoi avoir légiféré à la va-vite sur un tel sujet ? La rédaction retenue, loin d'être parfaite, soulève de réelles interrogations. Ses promoteurs estiment qu'il faut assurer une reconnaissance symbolique de la spécificité des animaux dans le code civil. Cela pose de graves questions de principe : une loi à vocation symbolique est-elle vraiment normative? Le code civil doit-il être un code symbolique? Je vous proposerai, pour l'ensemble de ces raisons, de supprimer cette disposition. Quant aux autres, je vous propose de maintenir les solutions précédemment adoptées par le Sénat, en particulier les garanties supplémentaires que nous avions votées" (FRANÇA, 2015b).

${ }_{13}$ No original: "Je ne partage pas votre avis : la portée symbolique d'une loi n'est pas forcément nulle. Le caractère d'être sensible reconnu à l'animal ne sera pas indifférent pour l'évaluation du préjudice subi par une victime en cas d'atteinte à ce bien meuble particulier. Je suis favorable au maintien de cet article" (FRANÇA, 2015b).
} 
(FRANÇA, 2015b) (grifo meu) ${ }^{14}$. Outro argumento mobilizado pelos contrários - em verdade, a maioria dos senadores a avaliar o mérito da matéria julgada - é que o movimento original do qual esse projeto é uma das iniciativas, entre outras, seria no sentido de "simplificar" a legislação, e isso, devido às potenciais ordens de problemas, indefinições e incertezas quanto aos efeitos de sua aplicabilidade, não deveria estar no mesmo bojo das demais reformas legislativas em curso.

A recepção do Senado ao projeto é, portanto, bastante ambígua e reticente. Apesar de algumas tentativas de supressão do reconhecimento jurídico dos animais no código civil pelos senadores, a iniciativa sagrou-se vencedora, especialmente naquilo que instaura: a senciência animal como legibilidade possível. Segundo o jornal The Local, a França obtém um poderoso lobby agrícola que, juntamente com alguns políticos, pressionou o Parlamento, expressando preocupação de que a mudança na legislação pudesse prejudicar os interesses dos agricultores e criadores de gado particulares ${ }^{15}$. A presença pública da ONG e a promoção de uma nova sensibilidade em relação aos animais - assim como, eu diria, a decisão da corte argentina em favor da orangotango Sandra poucos meses antes da promulgação da mudança na legislação francesa - parecem ter pavimentado o caminho para a aprovação da reforma no código civil francês, em fevereiro de 2015. Aqui, caberia fazer uma comparação avaliando retrospectivamente categorias e suas formas de emergência. No caso argentino, a prerrogativa garantida à Sandra como uma "pessoa não humana" é produzida pelo Direito, numa decisão judicial a respeito do "direito à liberdade de um orangotango" e de seu posterior acolhimento numa reserva natural - tudo isso tendo como matriz de relação o reconhecimento, pelo Judiciário, de que ela "tem sentimentos". Daí ser uma "pessoa não humana" com direito à liberdade. Tal seu deu sobre a avaliação a respeito de uma vida animal, individualizada por meio de registros específicos, entre os quais a ciência e o Direito - apesar do precedente legal que se abre naquele Estado

\footnotetext{
${ }^{14}$ No original: "Je suis d'accord avec le rapporteur: nous aimons tous les animaux, mais, quant à la procédure, l'introduction de cette disposition est inacceptable. Ses conséquences économiques pourraient en outre être tout à fait désastreuses" (FRANÇA, 2015b).

15 Fonte: AVANCINI, Alex. Em decisão histórica França altera Código Civil e reconhece animais como seres sencientes. In: JUSBRASIL. Notícias. [2014]. Disponível em: http://anda.jusbrasil.com.br/noticias/166696161/em-decisao-historica-franca-altera-codigo-civil-e-reconhece-animais-como-seres-sencientes. Acesso em: jul. 2017.
} 
a partir da jurisprudência produzida. $\mathrm{O}$ caso francês, ao que me foi permitido inferir, está sendo coproduzido por meio de outros caminhos: por reformas na legislação, no lugar de decisões judiciais e, o que considero mais pertinente, com pretensões regulatórias generalistas - em nome dos "animais".

\section{DA CONSCIÊNCIA À SENCIÊNCIA: INSCRIÇÕES E INTERSEÇÕES}

Em junho de 2012, durante a Francis Crick Memorial Conference, na Universidade de Cambridge, na Inglaterra, um conjunto de neurocientistas divulgou o Manifesto de Cambridge ${ }^{16}$, com o objetivo de "compilar as pesquisas da área" no que tange à verificação da "capacidade de consciência" dos animais. A grande constatação apresentada a público no texto assinado pelos 13 expoentes da área era a seguinte: os humanos não são os únicos animais com "estruturas neurológicas que geram consciência". Estas eram presentes em outros animais, entre os quais pássaros, macacos, elefantes, golfinhos, polvos, cães e gatos. A expertise dos neurocientistas e o renome das instituições em que atuam (Caltech, Universidade de Stanford, Massachusetts Institute of Technology e Max Planck Institute) foram muito mobilizados na época da replicação midiática do Manifesto e das entrevistas apresentadas com alguns desses pesquisadores. O fato de a explicação a respeito da capacidade de consciência dos animais ser resumida em termos de presença de "estruturas neurológicas" (especialmente o córtex cerebral), contudo, não resolve a questão, uma vez que vários pesquisadores signatários apresentam posicionamentos heterogêneos a respeito do que seria, afinal, "consciência".

Phillipe Low, em entrevista à Revista Veja (16 de julho de 12), defendera: "Quando seu cachorro está sentindo dor ou feliz em vê-lo, há evidências de que no cérebro dele há estruturas semelhantes às que são ativadas quando exibimos medo, dor e prazer". A mesma matéria trazia um depoimento desse neurocientista alegando que, após a descoberta, estava considerando tornar-se vegetariano. Outra pesquisadora acionada, Diana Reiss, exemplifica a

${ }^{16}$ Na íntegra em: LOW, Philip. The Cambridge Declaration on Consciousness. Julho de 2012. Disponível em: http://fcmconference.org/img/CambridgeDeclarationOnConsciousness.pdf. Acesso em: jul. 2017. 
consciência como a capacidade de autopercepção, como a de que são capazes golfinhos e elefantes em frente a um espelho, por exemplo (PIRES, 2012) ${ }^{17}$.

Em outra entrevista, Low é perguntado sobre se os "neurocientistas teriam se tornado militantes do movimento animal" e defende a postura tradicional da "neutralidade científica":

É uma questão delicada. Nosso papel como cientistas não é dizer o que a sociedade deve fazer, mas tornar público o que enxergamos. A sociedade agora terá uma discussão sobre o que está acontecendo e poderá decidir formular novas leis, realizar mais pesquisas para entender a consciência dos animais ou protegê-los de alguma forma. Nosso papel é reportar os dados (INSTITUTO BRASILEIRO DE ALTOS ESTUDOS DE DIREITO PÚBLICO, 2013) ${ }^{18}$.

A atividade cerebral similar à humana é tida como o parâmetro da capacidade de consciência nesses experimentos "reportados":

Entrevistador: Que tipo de comportamento animal dá suporte à ideia de que eles têm consciência?

Low: Quando um cachorro está com medo, sentindo dor ou feliz em ver seu dono, são ativadas em seu cérebro estruturas semelhantes às que são ativadas em humanos quando demonstramos medo, dor e prazer. Um comportamento muito importante é o autorreconhecimento no espelho. Dentre os animais que conseguem fazer isso, além dos seres humanos, estão os golfinhos, chimpanzés, bonobos, cães e uma espécie de pássaro chamada pica-pica (INSTITUTO BRASILEIRO DE ALTOS ESTUDOS DE DIREITO PÚBLICO, 2013).

Se os cérebros desses animais estariam mais próximos às "estruturas neurológicas dos humanos", isso não implicaria, para os neurocientistas, a produção de uma hierarquização entre seres mais ou menos "conscientes":

\footnotetext{
17 PIRES, Marco Túlio. Quase humanos. Veja. 16 jul. 2012. Disponível em: http://veja.abril.com.br/noticia/ciencia/quase-humanos. Acesso em: jul. 2017.

18 Fonte: INSTITUTO BRASILEIRO DE ALTOS ESTUDOS DE DIREITO PÚBLICO. Manifesto de Cambridge: consciência dos animais. Textos para debate. 28 out. 2013. Disponível em: http://www.altosestudos.com.br/?p=51966. Acesso em: jan. 2016.
} 
Entrevistador: É possível medir a similaridade entre a consciência de mamíferos e pássaros e a dos seres humanos?

Low: Isso foi deixado em aberto pelo manifesto. Não temos uma métrica, dada a natureza da nossa abordagem. Sabemos que há tipos diferentes de consciência. Podemos dizer, contudo, que a habilidade de sentir dor e prazer em mamíferos e seres humanos é muito semelhante (INSTITUTO BRASILEIRO DE ALTOS ESTUDOS DE DIREITO PÚBLICO, 2013) $)^{19}$.

Low, apresentado como redator principal, é uma das figuras mais recorrentes nas entrevistas relacionadas à replicação dessa "novidade científica". Outro dos pesquisadores entrevistados e também signatário do manifesto, David B. Edelman, defende uma definição de "consciência" em outros termos:

O que chamo de consciência, que não é necessariamente como os outros pesquisadores nesse campo definem o termo, é a ideia de uma cena integrada. Recebemos uma variedade de informações sensoriais - por exemplo, na visão, temos contraste, cor, forma, ângulos -, mas não interpretamos esses dados como entidades separadas, vemos a cena toda, de forma integrada. A consciência consiste na capacidade de perceber esse cenário integrado e mantê-lo em sua memória. Acredito que já se pode afirmar que essa habilidade existe em vários animais além dos humanos, bem mais do que suspeitávamos (INSTITUTO BRASILEIRO DE ALTOS ESTUDOS DE DIREITO PÚBLICO, 2013).

Com efeito, essa consciência não é necessariamente a mesma "consciência de si", como o exemplo do espelho. Para Edelman, essa capacidade específica de autopercepção seria aferível para algumas espécies, como papagaios e macacos, mas não poderia ser ainda generalizável a todos os animais, conforme o seu próprio conceito de consciência.

Entrevistador: Mas e nos outros animais?

Edelman: As coisas começam a ficar mais complicadas. Nas aves, por exemplo, sabemos agora que há bastante conservação evolutiva na anatomia cerebral em relação à nossa. Achava-se que as áreas do cérebro equivalentes ao córtex nesses animais eram estruturas primi-

19 Ibidem. 
tivas, mas os estudos dos últimos 40 anos revelaram que essa região, chamada de pálio, é o córtex das aves. As células que no embrião dos mamíferos dão origem ao córtex são as mesmas que no embrião das aves se transformam no pálio e no hiperpálio. Logo, o argumento de que as aves possam ter consciência é razoavelmente válido, já que o seu cérebro tem as características estruturais e, provavelmente, funcionais para tal (INSTITUTO BRASILEIRO DE ALTOS ESTUDOS DE DIREITO PÚBLICO, 2013).

Se a consciência parece ser desempenhada de formas múltiplas - conforme Mol (2007) - mas, como espero ter tornado claro, suficientemente articuláveis e sobreponíveis, importa para este debate a habilidade de interferência (MOL, 2007) que tal atuação da capacidade de consciência dos animais possa vir a ter nesses registros. Ou seja: os seus efeitos, na qualidade de políticas ontológicas em outros setores da realidade. Chamo atenção para duas delas, a que voltarei no final desta seção: a conformação da "consciência" como um efeito da atividade cerebral e a reordenação constante do par relacional humanidade-animalidade.

Antes disso, contudo, precisamos grafar uma passagem importante a respeito das ideias de "consciência" e "senciência", uma vez que designam fenômenos próximos e são utilizados como termos intercambiáveis com alguma frequência. O Manifesto de Cambridge, ancorado na ideia de consciência, defende uma mudança no nível ético-político quando diz: "Queremos que esses animais recebam direitos fundamentais, que a Justiça os enxergue como pessoas, no sentido legal" ${ }^{20}$.Conforme vimos até aqui, em alguma medida esse parece ser um movimento em curso. No entanto, é preciso matizá-lo: a "pessoa não humana" é precisamente uma, individualizada por um processo jurídico. A reforma na legislação francesa, segundo o já exposto, o faz em nome do reconhecimento da capacidade de sensibilidade do animal. Aqui, então, temos o incremento de uma ordem de argumentos em direção à senciência, muito embora o termo utilizado seja "sensibilité". Defendo que a transição da ordem de argumentos de "consciência" para "sensibilidade" traz alguns efeitos importantes para a discussão aqui realizada.

\footnotetext{
${ }^{20}$ Posição do pesquisador Steven Wise (PIRES, 2012).
} 
O debate no campo do ativismo dos direitos dos animais acerca das categorias de consciência e senciência é extenso, e recobri-lo é algo que foge dos objetivos deste artigo. Importa aqui mencionar que a ideia de senciência é elaborada por teóricos como Singer (2008) e pode ser resumida como a capacidade que o indivíduo tem de sentir prazer, alegria, medo, angústia, dor, tristeza. Em outra formulação, a aptidão de receber e reagir a um estímulo de forma consciente, experimentando-o a partir de dentro ${ }^{21}$. Em algumas ênfases, assim, a senciência engloba a consciência porque pressupõe uma reação consciente. Porém, em quase todas as definições disponíveis a respeito da senciência, trata-se de explicitar a capacidade de sentir, a sua sensibilidade - daí o seu tratamento aqui como categorias intercambiáveis (senciência e sensibilidade).

A consciência, segundo as atuações que vimos na perspectiva dos neurocientistas, está muito mais relacionada à posse de um sistema nervoso centralizado e, especialmente, identificação de estruturas neurológicas que reagem proximamente às humanas. Algumas leituras do ativismo dos direitos dos animais, com efeito, parecem não se satisfazer com essas definições: numa delas ${ }^{22}$, por exemplo, enfatiza-se a capacidade de experienciar que tem o animal em sua sensibilidade (esta oriunda de sua consciência que, no limite, é um epifenômeno da atividade de seu sistema nervoso). Essas experiências podem ser positivas (desfrute) ou negativas (sofrimento), em uma leitura que se dá com base na aferição de "benefícios" e "danos". O sofrimento, portanto, é evitável e reconhecível - e, se quisermos, podemos vê-lo segundo instrumentos "científicos", entre os quais os ofertados pela neurociência. Sensibilidade, senciência e consciência, embora sem dúvida cheguem a designar processos diferentes - eles próprios eventualmente atuados de formas múltiplas (MOL, 2007) -, podem ser justapostas aqui sem grandes dificuldades: inclusive, reforçam-se, englobam-se; reúnem, enfim, um movimento mais amplo que podemos agora entender.

No bojo mais geral desse movimento podemos identificar que o uso de animais "para o livre proveito do homem" como uma caixa-preta, no sentido

${ }^{21}$ ÉTICA ANIMAL. O que é senciência. [s.d.]. Disponível em:https://www.animal-ethics.org/senciencia-secao/introducao-a-senciencia/senciencia-animal/. Acesso em: jan. 2016.

${ }^{22}$ Está, por exemplo, no cerne da definição de "senciência animal" da organização Animal Ethics, Inc (http://www.animal-ethics.org/senciencia-animal/). 
de Latour (1994), passa a ser questionado a partir de uma inflexão que se dá por múltiplos actantes, como legisladores, operadores do Direito e neurocientistas que instauram a consciência dos animais, intermediários científicos diversos e seres humanos "ativistas". Desta forma, ciência, laboratório, neurônios, manifestos e revistas inscrevem a senciência dos animais, registram actantes e fazem traduções dessas "descobertas" em termos de debate moral, político e normativo (LATOUR, 1994). Como vimos, muito desse esforço de aproximação entre as consciências humana e a animal se faz em nome da posse de um "córtex cerebral" e de um "sistema nervoso centralizado", cujo ápice evolutivo parece remeter irremediavelmente ao humano. Mesmo sem as valorações gradualistas que os neurocientistas de Cambridge intentam rejeitar, essa avaliação subjaz ao entendimento do que é consciência e, por conseguinte, da capacidade sensível relacionada à senciência.

A matriz dessa aproximação, contudo, tem contornos muito interessantes, especialmente tendo em vista a agência privilegiada dada num nível biológico molecular ao cérebro - um fisicalismo reducionista muito característico das interpretações em neurociência (AZIZE, 2008, 2010). Como Rohden (2012) já havia sugerido, o processo de redefinição de fronteiras entre o que é tido como natural e o social pela biomedicina tem passado por novas ênfases, nas quais é fundamental o acionamento de discursos reducionistas centrados em genes, hormônios e, do que estou falando aqui, cérebros. De fato, como aponta Duarte (1999), o papel no Ocidente da categoria "nervoso", após a passagem de um modelo calcado no "sangue", e do "cérebro", como órgão que registra as memórias e organiza os sentidos, na noção de pessoa vigente, traz em si possibilidades de articulação dos nossos dispositivos de sensibilização com o uso de tecnologias. O enquadramento em um nível cada vez mais molecular de tais fenômenos possibilita, como formulou Monteiro (2012), manipular o corpo, a fim de politizar a vida, um movimento que comporta distintos vetores de atuação.

Se grande parte das narrativas de tom biologizante e naturalista substancializa diferenças (ROHDEN, 2012), eu gostaria de sugerir que elas também podem, por meio de certa criatividade dos agentes, gerar aproximações, como a entre humanos e animais. Neste debate, considero importante termos em vista a produção de continuidades que estas empreendem e seus efeitos públicos. Contudo, também existem outros efeitos - "capacidades de interfe- 
rência", como explica Mol (2007) - atinentes ao movimento que produz aproximações entre a "capacidade de sentir" dos seres humanos e dos animais - que incorrem em aspectos relacionados à própria negociação do estatuto ontológico entre entes (DESCOLA, 2015). Aproximando-se deste debate a partir da produção de ordens legais sobre os "direitos dos animais", Descola (2008) se vale dos próprios vetores acionados nesses debates (como os dos "sentimentos" para com os animais em situações "de tratamento negativo") e demonstra como tal situação, no lugar de colapsar a partição entre natureza e cultura que em parte fundamenta a hierarquia basilar entre humanos e animais, termina por aprofundar a ontologia naturalista ${ }^{23}$. Contudo, o sentido de "hierarquia" tende a se reatualizar, como voltarei a tratar adiante, sob a forma de imperativos morais de responsabilização.

Pensando essas elaborações sobre consciência animal e sua consequente capacidade de senciência, creio que estamos diante de um "deslocamento suscitado por novos conhecimentos", no sentido pretendido por Strathern (1995, p. 347), a partir de um tornar explícito o implícito: assim, no caso que aqui analiso, a possibilidade técnica de identificar processos de atividade neurológica dos humanos parece ter provocado reordenamentos de pensar os próprios valores de consciência de si, autonomia e capacidade de significar experiências - tidos, a partir de uma filosofia política forjada entre os séculos XVII e XVIII, como privilégios dos seres humanos, ou, melhor dito, de alguns deles.

Uma vez que já foi arguido se o que a ciência via nos cérebros era a pequena diferença entre os sexos ou a grande diferença entre os gêneros ( $\mathrm{ROH}$ DEN, 2010), creio que estamos diante de uma pergunta análoga a respeito do que é acionado para identificação interespecífica e as suas consequências: o

\footnotetext{
23 "Proteger os animais outorgando-lhes direitos - ou impondo aos humanos deveres para com eles - é apenas estender a uma nova classe de seres os princípios jurídicos que regem as pessoas, sem colocar em causa de maneira fundamental a separação moderna entre natureza e sociedade. A sociedade é fonte do direito, os homens o administram, e é porque são condenadas as violências para com os humanos que as violências com relação aos animais se tornam condenáveis. Não é nada disso para numerosas sociedades pré-modernas, que, encarando os animais não como sujeitos de direito tutelado, mas como pessoas morais e sociais plenamente autônomas, se empenham tão pouco em estender-lhes sua proteção, quanto julgam desnecessário velar pelo bem-estar de vizinhos distantes. Decidir tratar a natureza com respeito e benevolência supõe que a natureza exista - e também, sem dúvida, que tenha sido primeiramente maltratada. Quando a natureza não existe sob a forma de uma esfera autônoma, a relação com os animais só pode ser diferente da nossa, e a questão sobre matar um animal só pode se colocar em termos muito distintos daqueles que nos são familiares” (DESCOLA, 1998, p. 25).
} 
que se vê, afinal, nos cérebros de animais e de humanos? A pequena diferença entre o desenvolvimento de sistemas nervosos ou a grande diferença entre o estatuto a ser outorgado em cada espécie? Uma semelhança suficiente para reconhecer sua similitude? O aprofundamento da condição de humanidade (como explicita Ingold (1995)) a partir daquilo que passa a ser valorizado?

Ao formular de tal maneira o movimento que identifico em relação às formas de atuação da senciência mediadas por possibilidades e arranjos sociotécnicos complexos, creio estar em consonância com uma agenda de pesquisa que persegue questões tanto da ordem do "sentir" e da composição no espaço público de comunidades emocionais quanto da produção de novos ordenamentos legais e normativos. Assim, essa perspectiva trava um diálogo de fundo com diversos estudos que têm feito emergir os sentidos de "explicitação do implícito", materializando concepções e disputas por meio de aparatos sociotécnicos ${ }^{24}$.

\section{A CAPTURA DA SENSIBILIDADE: ENTRE AS EMPATIAS IMAGINADAS E A VIDA EMOTIVA DO FISICALISMO CIENTÍFICO}

Segundo a historiadora dos direitos humanos Lynn Hunt, a ideia dos direitos humanos decorreria também de duas mudanças sutis nas noções de corpo e identidade: uma ampliação da percepção de individualidade corpórea, que tornaria cada homem detentor de direitos sobre si, e a possibilidade de haver uma "empatia imaginada" entre psiques que, apesar de distintas, se percebem como integrantes de uma mesma humanidade (HUNT, 2005, p. 268). Ao propor um modelo "psicocultural" para compreender a emergência

\footnotetext{
${ }^{24}$ Como, por exemplo, os testes de ancestralidade genética negociando identidades étnicas (GASPAR NETO; VENTURA-SANTOS, 2011); a autonomização do feto por meio da embriologia e dos exames de imagem e seus usos nos debates sobre o "direito à vida" (LUNA, 2009); as negociações acerca da similitude entre DNAs de chimpanzés e humanos na avaliação de juristas sobre os direitos dos primeiros à liberdade por via de um habeas corpus (BEVILACQUA, 2011); a constituição de "consensos médicos" a respeito das classificações e diagnósticos sobre a intersexualidade e seus efeitos regulatórios provenientes de categorias médicas na produção de separações e clivagens entre corpos (MACHADO, 2008); ou, ainda, a própria racionalidade biomédica metrificando terapias holísticas baseadas nos efeitos da "espiritualidade" na saúde (TONIOL, 2018).
} 
e a consolidação dos direitos humanos em um contexto de marcadas assimetrias sociais, a autora joga luz nos significados vigorantes nos textos e declarações de "direitos do homem e do cidadão" feitas entre os séculos XVII e XVIII, chegando até os "droits de l'homme":

Se os proponentes dos direitos humanos universais, iguais e naturais, contudo, excluíam algumas categorias de pessoas do exercício desses direitos, isso ocorria principalmente porque eles não os viam como inteiramente autônomos: os escravos, as crianças, e os loucos, mais obviamente; mas também (quase tão obviamente, para as pessoas do século XVIII), os criados, os sem-propriedade, e as mulheres (HUNT, 2005, p. 274).

A autonomia moral individual requereria dois desenvolvimentos concomitantes para o seu "reconhecimento": a ampliação do sentimento de separação dos corpos humanos (e um conseguinte respeito ao corpo alheio) e uma ampliação no sentimento de empatia entre psiques separadas no espaço (uma identificação de semelhança em algum aspecto fundamental). Logo, para ser considerada autônoma, uma pessoa tem que estar legitimamente individualizada e protegida em sua separação em relação aos outros. Porém:

[...] Para obter direitos que acompanhem essa separação corporal, a individualidade da pessoa tem que ser valorizada de um modo mais afetivo ou emocional. Os direitos humanos dependem tanto de que se seja dono de si mesmo quanto do reconhecimento de que todos os outros são igualmente donos de si (HUNT, 2005, p. 275).

Um aspecto fundamental para que isso ocorra é a tal "empatia imaginada" que, como Hunt (2005) demonstra, foi muito influenciada por meio da massificação do romance epistolar (narrativas protagonizadas por personagens de baixos estratos sociais e consumidos por classes letradas), pois esses textos teriam tornado possíveis novos tipos de identificação psicológica. Desta forma, embora um autor como Rousseau seja responsável pela expressão "droits de l'homme", a escritora salienta que a sua autoria de romances - como Julie, or The new Heloise, um best-seller de efeito catártico mencionado por 
Hunt $^{25}$ - pode ter sido tão influente para o desenvolvimento dos direitos humanos quanto $O$ contrato social.

Com efeito, a ciência tem ofertado interpretações - como as que vimos no item anterior - que poderiam fornecer aos agentes do Estado (legisladores e juízes) bases para que essa discriminação ontológica se assente de forma mais legitimada. O repertório da ciência também gera aproximações entre humanos e não humanos de formas para além dos marcos legais, como já havia sugerido Segata (2012), com base em um problema próximo ao que aqui analiso: a medicalização de pets em centros urbanos desde diagnósticos médicos. Uma das consequências desse fenômeno é justamente a possibilidade de negociações em torno da humanidade dos animais de estimação, a partir da sua percepção como "descontínuos, mas equivalentes", do ponto de vista das "correlações orgânicas/naturais" (SEGATA, 2012, p. 197). Também a alimentação e a "dieta dos pets" foram alvo de intensa problematização em relação a disputas sobre sua adequação quando de diferentes contextos (LEWGOY; SORDI, 2012). Inclusive, mobilizaram o aparelho judiciário e a polícia em casos "constatados" de "negligência" da alimentação dos animais (KULICK, 2009).

Se a ciência tem um bom repertório para falar da "sensibilidade animal de suas necessidades" em relação a interseções da vida nos grandes centros urbanos, ela também propõe discussões sobre seu próprio estatuto e de suas capacidades, conforme o que já desenvolvi no item anterior. Em grande medida, a (neuro)ciência parece ter assumido uma abordagem gradualista a respeito das capacidades de senciência e consciência, em geral mensuráveis a partir do "nível de desenvolvimento" do sistema nervoso centralizado em cada espécie.

\footnotetext{
25 A maior parte dos romances consumidos e avaliados pela autora é protagonizado por criadas, mulheres em busca de libertação em contextos em que esta lhes é negada e que, confrontadas constantemente com o assédio moral de seus superiores, dão grandes mostras de uma superioridade moral que seu status social e legal, porém, não acompanha: "Aparentemente, as antinomias entre autonomia e dependência, liberdade e coerção, não poderiam ser experimentados de forma mais intensa que através de personagens que só podiam aspirar pela autonomia, mas nunca alcançá-la por completo, ou seja, as mulheres. Uma questão fundamental esconde-se nesse paradoxo: se as mulheres podiam ser apresentadas como sendo tão nobres, tão intensamente humanas, tão desejosas de liberdade, então, como elas podiam ser privadas de seus direitos? Os homens, e as mulheres também, realizariam um grande esforço, através dos séculos XIX e XX, para encontrar uma resposta” (HUNT, 2005, p. 281).
} 
Essa métrica científica prevê, portanto, o desenvolvimento completo das capacidades de sentir e significar no ser humano, que se torna, assim, o parâmetro destas por excelência, expressando - por que não? - valores, dadas as agências que acionam nos debates a respeito dos regimes legais.

Como Tim Ingold já defendera em 1995, a própria concepção de animalidade é uma construção a partir do par relacional humanidade, tida como uma deficiência de tudo o que apenas nós, os humanos, supostamente temos, inclusive a linguagem, a razão, o intelecto e a consciência moral (INGOLD, 1995, p. 1). A promoção da especificidade da condição de humanidade fez com que, segundo esse autor, a relação entre o humano e o animal deixasse de ser inclusiva ("uma província dentro de um reino") e passasse a ser exclusiva ("um estado alternativo do ser”) (INGOLD, 1995, p. 5). Tal concepção redundou um aprofundamento do dualismo natureza-cultura, nos termos de que a humanidade seria dividida, com "uma parte imersa na condição física da animalidade, e a outra na condição moral da humanidade" (INGOLD, 1995, p. 6). Versando sobre a Declaração Universal dos Direitos do Homem, o autor cita o seu artigo primeiro, segundo o qual "todos os seres humanos são dotados de razão e consciência”. Por esta inscrição, fica implícito que os animais não humanos não o são (INGOLD, 1995, p. 9).

Ingold (1995) situa também os defensores de uma "continuidade" entre os animais e os seres humanos, em geral chamados de "gradualistas", para quem as características que definem a "excepcionalidade da espécie humana" são diferentes em grau, e não em espécie.

[Os gradualistas] alegam que, embora a linguagem humana possa ser extremamente versátil, ela não difere fundamentalmente dos sistemas de comunicação usados por outros animais; sendo assim, é perfeitamente legítimo fazer referência à "linguagens dos animais". Na mesma linha de raciocínio, embora concordando em que os seres humanos têm uma inteligência superior, os gradualistas alertam contra a subestimação da inteligência dos outros animais - que, por sinal, tendem muito menos a cometer erros do que nós. Embora reconhecendo o alcance e a complexidade sem paralelos dos desígnios humanos, os gradualistas observam que as habilidades construtivas de animais não humanos não podem ser negligenciadas. Insistir, contra todas as evidências, na existência de linguagem, inteligência e engenhosidade nos animais, afirmar que os seres humanos continu- 
am sendo diferentes em espécie, dizem os gradualistas, é adotar uma atitude antropocêntrica insensata, que não deveria ter cabimento na pesquisa científica racional (INGOLD, 1995, p. 12).

Ao negarem uma concepção de humanidade como "um estado de tudo-ou-nada", gradualistas a veem como uma escala contínua que mede o desempenho real de populações animais e humanas. Não se trataria, aqui, de ter ou não ter linguagem, razão, consciência: de acordo com essa forma de reflexão, os animais podem ser mais ou menos dotados dessas aptidões ou qualidades. Tal me parece ser o esquadrinhamento da consciência pelos neurocientistas de Cambridge, entendendo que a valorização da semelhança do animal à capacidade humana de ser consciente pode figurar como relativamente mensurada e inteligível numa inscrição científica para depois ser replicada como uma "descoberta científica", e daí em diante ganhar o mundo dentro de disputas em outros domínios, como o do Direito.

Um dos efeitos da abordagem gradualista parece ser o reforço à valorização de faculdades localizadas, como a ênfase à racionalidade. Assim, reivindicando a existência de diferenças de grau, não seria possível deixar de postular uma escala universal de progresso, em relação à qual os homens e os outros animais são situados em posições de "mais" ou "menos". Para Ingold (1995), tal operação nega o antropocentrismo, mas recai sobre o etnocentrismo, ao postular uma humanidade típica, a partir da qual os demais sujeitos e seres são valorados (INGOLD, 1995, p. 14).

Eventualmente, outros antropólogos abordaram o tema a partir do conceito de cultura, como Clifford Geertz (1980) que, ao avaliar as descobertas da antropologia física e da paleontologia, refutou a teoria do ponto crítico de Alfred Kroeber ${ }^{26}$ sobre a capacidade de adquirir cultura a partir de uma leitura gradualista. Assim, aquele autor viu nos cérebros nuances entre o estado de animalidade e o da humanidade pelos argumentos mobilizados pela paleontologia a respeito do "salto para a humanidade": "descobriram-se" fósseis com "corpos de seres humanos" (Homo sapiens) com "cérebros de símios". Essas espécies de seres intermediários apresentariam aptidões

\footnotetext{
${ }^{26}$ A teoria do ponto crítico defende que a cultura é um estado de "tudo-ou-nada", passando a ser desenvolvida como um fenômeno espontâneo, que ocorre após a formação neurológica do homem. Ver Geertz (1980).
} 
humanas, como a postura semiereta e as práticas de caça e coleta, mas ainda não teriam desenvolvido uma linguagem "como a humana", e seus cérebros corresponderiam a um terço da massa do ser humano atual. Nessa análise, Geertz (1980) afirma que tais seres teriam uma protocultura, donde conclui que a capacidade de adquirir cultura é gradual e contínua. Essa postura é muito próxima, guardadas as diferenças de aproximação entre os dois campos de conhecimento, da forma pela qual a neurociência tem manejado a ideia de consciência.

Por essa aproximação com o ponto de vista geertziano, gostaria apenas de frisar o fato de que este discurso a respeito das condições de humanidade como uma identificação possível por meio de uma "verdade biológica" é disseminado por diferentes agentes, que terminam por produzir uma determinada concepção de humanidade, de animalidade e de natureza e cultura - mesmo quando ofertam graduações entre esses domínios. Também, muito embora haja a abordagem reducionista subjacente às substancializações fiscalistas aqui acionadas, os termos em questão são passíveis de justaposição ou, melhor dizendo, hibridização entre os dois polos que preveem.

\section{CONSIDERAÇÕES FINAIS: DA PROXIMIDADE À RESPONSABILIZAÇÃO, A MORAL NA AGENDA DA SENCIÊNCIA}

Ainda que o argumento da sensibilidade dos animais esteja, como vimos no exposto a respeito da consciência, ancorado em uma retórica cientificista, é importante lembrar que, especialmente no caso da reforma legislativa ocorrida na França, a proposição original foi movida por uma organização não governamental, a qual poderíamos chamar de "animalitária" (DIGARD, 1999). A Fondation 30 Millions d'Amis, cuja uma das causas centrais era a luta em nome do reconhecimento do estatuto jurídico do animal como ser sensível, apresenta-se especialmente envolvida nas "causas animais" relacionadas aos animais de companhia (pets), entre os quais gatos, cães, cavalos, furões, coelhos, cobaias, ratos, hamsters, canários, periquitos, papagaios, 
répteis de terrário, peixes dourados e peixes tropicais ${ }^{27}$. Sua ação parece se localizar, acerca dos pets, em iniciativas de auxílio, adoção, pedagogização contra o seu abandono e combate aos maus-tratos. Em menor grau, salienta proposições em direção à condenação das touradas e dos "abusos da caça", de acabar com o "massacre animal" na busca por peles e abolir a experimentação nas indústrias. Ainda refere como causas a proibição de animais em circos e o fim do tráfico animal - além do reconhecimento jurídico, nosso foco aqui, dos animais como seres sensíveis.

Essas ações que refletem um entendimento do animal como um próximo (SORDI, 2011) trazem interseções com a retórica do ativismo abolicionista em vários momentos, muito embora a grafada ênfase na ação dessa Fundação em direção aos pets. Isto poderia ser aferido, por exemplo, pelo fato de que, apesar de as iniciativas mais fortes da organização serem relacionadas aos animais identificados como de estimação, a sua proposição legal tinha um tom generalista: previa a extensão do "reconhecimento da capacidade sensível" a todos os animais. Neste sentido, pode-se dizer que suas ações animalitárias estão entre o bem-estarismo e o abolicionismo ${ }^{28}$, vez que o segundo preveria certa indiferença frente às necessidades humanas, e uma das causas que a Fundação defende é o "uso de animais para reabilitação de pessoas emocionalmente frágeis". Logo, a aproximação entre seres humanos e animais mostra-se ambígua e parece ser mais inteligível a partir do processo de intersubjetividade: a própria palavra "amis" no título da Fundação dá mostras do tipo de subjetivação de que estamos diante.

\footnotetext{
27 Ver: FONDATION 30 MILLIONS D’AMIS. La fondation. Nos combats. Paris: Fondation 30 Millions d’Amis, [2017]. Disponível em: http://www.30millionsdamis.fr/la-fondation/nos-combats/_Acesso em: jan. 2016.

${ }^{28}$ Os movimentos que promovem os direitos dos animais, embora possuam notáveis convergências quando da ação junto a casos concretos, apresentam bem grafadas distinções de ênfase. Para os abolicionistas, o objetivo é promover uma ênfase nos direitos, universais e abstratos, reconhecidos como legítimos após um processo de esclarecimento. Já os bem-estaristas encabeçariam uma "ênfase nos afetos, geridos como que espontaneamente através da tendência de empatizarmos com tudo aquilo que pareça reunir traços de uma 'semelhança de interioridade"' (SORDI, 2011, p. 16) (grifos meus).
} 
No caso específico da promoção da categoria "senciência animal" 29 pela neurociência, a própria replicação e divulgação das capacidades de diferenciar "prazer" e "dor" coloca os arranjos interespecíficos entre humanos e animais numa perspectiva moral. Embora a retórica da consciência seja problematizada (como já expus brevemente) por alguns grupos de ativismo em prol dos animais (e o mesmo pode ser dito em menor grau acerca da senciência, um termo fortemente difundido neste meio), ela parece trazer importantes implicações regulatórias, ou pelo menos implicações morais. Lembremos que um dos neurocientistas que assinam o Manifesto de Cambridge, quando da "constatação da capacidade de sentir dor e prazer pelos animais", alegou que estava considerando tornar-se vegetariano. Acredito poder dizer que negociações a respeito do estatuto jurídico do animal têm concorrido com representações científicas sobre uma proximidade dos animais com uma condição de humanidade, o que traz consequências morais e éticas - inclusive reinscrevendo em certo sentido as condições a respeito do que é "bioética".

Com efeito, os processos de que tratamos, embora ainda em disputa uma disputa que, aliás, salienta a própria multiplicidade ontológica da capacidade de sentir -, demonstram como imperativos morais são depreendidos do trabalho de diferentes agentes e da veiculação de seus argumentos sobre o que é sentir e quais são as implicações deste outro ter senciência sobre as ações humanas. Em alguma medida, pode-se perceber que o trabalho de politização das relações movido pela agenda da senciência está ambiguamente ligado à "economia socioemocional da compaixão" que, como analisa Clark (1997), anima hierarquicamente os polos da relação, porque manobra vínculos en-

\footnotetext{
29 Com efeito, mesmo a convergência das distintas atuações de consciência, senciência e sensibilidade não parecem chegar a problematizar absolutamente a tese do excepcionalismo humano: mesmo que se fale em graduações de capacidade de sentir (distinguir dor e prazer), memorizar, de "significar uma cena" ou de autopercepção dos animais, não são discutidas capacidades para a racionalidade, a linguagem ou para relações de moralidade, por exemplo. Talvez estes limites sejam tão óbvios que a neurociência se furte a discuti-los até o momento. Talvez eles estejam presumidos, por exemplo, dentro de retóricas totalmente cientificistas, como a percepção do medo apreendida por meio da atividade cerebral canina e de sua similitude da performance cerebral de um ser humano, como a aludida no exemplo do cientista. Afinal, sentir medo é uma deliberação a partir da compreensão de cenários de possibilidades e, portanto, dentro deste registro, só pode incorrer num juízo classificatório, visto que o contrário seria dizer que a resposta da atividade cerebral humana é “instintiva como a de um cão". Porém, esta é um tipo de inferência e divagação a que gostaria de me furtar nessas conclusões. Entendo, então, a senciência como uma forma de agência específica. Uma identificação de interioridade posta em relação que a situa num plano de continuidade (DESCOLA, 2015), identificando o outro como um próximo ou um aproximado na medida em que se equiparam determinadas características por meio de cadeias de mediação.
} 
tre os seres, como uma reação (de um presumivelmente superior) à miséria alheia (apud COELHO, 2006, p. 45). Em parte, o trabalho criativo dos atores na produção de "empatias imaginadas" (HUNT, 2005) parece ser reatualizado por essas práticas, visto que, como defendi em diferentes momentos deste trabalho, coloca a sensibilidade do ser humano como matriz de referência para a aferição da senciência conectada aos outros seres.

Do ponto de vista moral, contudo, as implicações dessa configuração não são nem de longe neutras a respeito do caráter de responsabilização que emerge a partir do reconhecimento da sensibilidade animal. Discutindo a noção de felicidade, Walker (2015) situa a passagem do debate utilitarista sobre a responsabilização da felicidade alheia e bem comum ao perceber como a noção de felicidade pode ser vista como um metavalor, traduzindo valores morais, embora tenha, a princípio, em si mesma, um caráter bastante vago. Dentro do caso de que tratamos aqui, é fundamental perceber que a distribuição de responsabilização incorre em uma hierarquização: dos seres humanos aos demais animais. É possível verificar, numa palavra, que a senciência traz em si pretensões regulatórias. Sua conformação como categoria de reconhecimento político, ainda, pode indicar novas formas de trabalhar publicamente com a dimensão das emoções, da moral e da prática científica hegemônica na produção de razões de verdade - o que aponta, também, para o próprio caráter "sensível" da fundamentação de nossas práticas.

\section{REFERÊNCIAS BIBLIOGRÁFICAS}

1. AVANCINI, Alex. Em decisão histórica França altera Código Civil e reconhece animais como seres sencientes. In: JUSBRASIL. Notícias. [2014]. Disponível em: http://anda.jusbrasil.com.br/noticias/166696161/em-decisao-historica-francaaltera-codigo-civil-e-reconhece-animais-como-seres-sencientes. Acesso em: 05 jul. 2017.

2. AFP. Agence France Presse. Sandra, a orangotango, vira celebridade da luta pelos direitos dos animais. In: ESTADO DE MINAS. Internacional. 22 dez. 2014. Disponível em: https://www.em.com.br/app/noticia/internacional/2014/12/22/ interna_internacional,601840/sandra-a-orangotango-vira-celebridade-da-lutapelos-direitos-dos-animais.shtml . Acesso em: 04 jul. 2017. 
3. AGAMBEN, G. O amigo \& O que é um dispositivo? Chapecó: Argos, 2014.

4. AGAMBEN, G. O reino e a glória: uma genealogia teológica da economia e do governo. São Paulo: Boitempo, 2009.

5. AZIZE, R. L. O cérebro como órgão pessoal: uma antropologia de discursos neurocientíficos. Trabalho, Educação e Saúde, Rio de Janeiro, v. 8, p. 563-574, 2010.

6. AZIZE, R. L. Uma neuro-weltanschauung? Fisicalismo e subjetividade na divulgação de doenças e medicamentos do cérebro. Mana, Rio de Janeiro, v. 14, p. 7-30, 2008.

7. BEVILACQUA, C. B. Chimpanzés em juízo: pessoas, coisas e diferenças. Horizontes Antropológicos, Porto Alegre, v. 35, p. 65-102, 2011.

8. BUTLER, J. Capacidade de sobrevivência, vulnerabilidade, comoção. In: BUTLER, J. Quadros de guerra. Quando a vida é passível de luto? Rio de Janeiro: Civilização Brasileira, 2015.

9. CLARK, C. Misery and Company: simpathy in everyday life. Chicago \& London: The University of Chicago Press, 1997.

10. COELHO, M. C. Emoção, gênero e violência: experiência e relatos de vitimização. Revista Brasileira de Sociologia das Emoções, João Pessoa, v. 13, n.5, 2006.

11. DESCOLA, P. Além de natureza e cultura. Tessituras, Pelotas, v. 5, n. 1, p. 7-33, 2015.

12. DESCOLA, P. Estrutura ou sentimento: a relação com o animal na Amazônia. Mana, Rio de Janeiro, v. 4, n. 1, p. 23-45, 2008.

13. DIGARD, J-P. Les français et leurs animaux. Paris : Fayard, 2003.

14. DUARTE, L. F. D. O império dos sentidos: sensibilidade, sensualidade, sexualidade na cultura ocidental moderna. In: HEILBORN, M.L. Sexualidade. O olhar das Ciências Sociais. Rio de Janeiro: Zahar, 1999.

15. ÉTICA ANIMAL. O que é senciência. [s.d.]. Disponível em:https://www.animalethics.org/senciencia-secao/introducao-a-senciencia/senciencia-animal/. Acesso em: 10 jan. 2016.

16. FASSIN, D. Introduction: towards a critical moral anthropology. In: FASSIN, D. (Org.). A companion to Moral Anthropology. Oxford: Willey-Blackwell, 2012.

17. FONDATION 30 MILLIONS D’AMIS. Statut juridique: de nouveaux espoirs pour (tous) les animaux. In: FONDATION 30 MILLIONS D’AMIS. La fondation. Nos combats. Paris: Fondation 30 Millions d'Amis, [2017]. Disponível em: http:// www.30millionsdamis.fr/la-fondation/nos-combats/exiger-un-statut-juridiquede-lanimal. Acesso em: 05 jan. 2017. 
18. FRANÇA. Code Civil des Français. 1804. Disponível em: http://www.assembleenationale.fr/evenements/code-civil-1804-1.asp. Acesso em: 12 set. 2019.

19. FRANÇA. Loi n 2015-177 du 16 février 2015. Relative à la modernisation et à la simplification du droit et des procédures dans les domaines de la justice et des affaires intérieures (1) - Article 2. In: LEGIFRANCE. Accueil. Les autres textes législatifs et réglementaires. [2015a]. Disponível em: http://www.legifrance. gouv.fr/eli/loi/2015/2/16/2015-177/jo/article_2. Acesso em: 06 jul. 2017.

20. FRANÇA. SÉNAT. Comptes Rendus de la Commission des Lois. Travaux parlementaires. 14 jan. 2015. [2015b]. Disponível em: http://www.senat.fr/ compte-rendu-commissions/20150112/lois.html. Acesso em: 06 jul. 2017.

21. FRANÇA. SÉNAT. Projet de loi relatif aux animaux dangereux et errants, et à la protection des animaux. In: SÉNAT. Travaux parlementaires.[1998]. Disponível em: http://www.senat.fr/rap/l97-429/197-4294.html . Acesso em: 07 jul. 2017.

22. GASPAR NETO, V. V.; VENTURA-SANTOS, R. Biorrevelações: testes de ancestralidade genética em perspectiva antropológica comparada. Horizontes Antropológicos, Porto Alegre, v. 17, n. 35, p. 227-256, 2011.

23. GAUCHAZH. Orangotango Sandra, pessoa "não humana" na Argentina, ganha lar no Brasil. In: GAUCHAZH. Geral. 01 out. 2015. Disponível em: https:// gauchazh.clicrbs.com.br/geral/noticia/2015/10/orangotango-sandra-pessoanao-humana-na-argentina-ganha-lar-no-brasil-4860599.html. Acesso em: 08 jul. 2017.

24. GEERTZ. C. Transição para a humanidade. In: ENGELS, R.; GEERTZ, C.; BAUMAN, Z.; LEONTIEV, A.; MARCARIAN, E. O papel da cultura nas ciências sociais. Porto Alegre: Editorial Villa Martha, 1980. Disponível em: http://www. afoiceeomartelo.com.br/posfsa/Autores/Martha,\%20Villa/O\%20Papel\%20 da\%20Cultura\%20nas\%20Ciencias\%20Sociais.pdf. Acesso em: 09 jul. 2017.

25. G1. Tribunal argentino deve decidir destino de orangotango 'triste' de zoo. In: G1. Natureza. 28 mai. 2015. Disponível em: http://g1.globo.com/natureza/ noticia/2015/05/tribunal-argentino-deve-decidir-destino-de-orangotangotriste-de-zoo.html. Acesso em: 08 jul. 2017.

26. HUNT, L. O romance e as origens dos Direitos Humanos: interseções entre história, psicologia e literatura. Varia História, Minas Gerais, v. 21, n. 34, p.267$289,2005$.

27. INGOLD, T. Humanidade e animalidade. ANPOCS: Revista Brasileira de Ciências Sociais, Caxambu, v. 10, n. 28, 1995 [1994]. Disponível em: http://www. anpocs.org.br/portal/publicacoes/rbcs_00_28/rbcs28_05.htm. Acesso em: 10 jul. 2017. 
28. INSTITUTO BRASILEIRO DE ALTOS ESTUDOS DE DIREITO PÚBLICO. Manifesto de Cambridge: consciência dos animais. Textos para debate. 28 out. 2013. Disponível em: http://www.altosestudos.com.br/?p=51966. Acesso em: 11 jan. 2016.

29. KULICK, D. Animais gordos e a dissolução da fronteira entre as espécies. Mana, Rio de Janeiro, v. 15, n. 2, p. 481-508, 2009.

30. LATOUR, B. Jamais fomos modernos: ensaios de antropologia simétrica. São Paulo: Editora 34, 1994.

31. LEWGOY, B.; SORDI, C. Devorando a carcaça: contracozinhas e dietas alternativas na alimentação animal. Anuário Antropológico 2011, Brasília, v. 2, p. 159-175, 2012.

32. LEWGOY, B.; SORDI, C.; PINTO, L. Domesticando o humano: para uma Antropologia Moral da proteção animal. Ilha. Revista de Antropologia, Florianópolis, v. 17, p. 75-100, 2015.

33. LOW, Philip. The Cambridge Declaration on Consciousness. Julho de 2012. Disponível em: http://fcmconference.org/img/ CambridgeDeclarationOnConsciousness.pdf. Acesso em: 12 jul. 2017.

34. LUNA, N. Embriões de laboratório e fetos anencefálicos: a constituição de sujeitos de direitos no debate público. In: DUARTE, Luiz Fernando Dias; GOMES, Edlaine de C.; MENEZES, Raquel Aisengart; NATIVIDADE, Marcelo (Orgs.). Valores religiosos e legislação no Brasil: a tramitação de projetos de lei sobre temas morais controversos. Rio de Janeiro: Garamond, 2009.

35. MACHADO, P. S. Intersexualidade e o "Consenso de Chicago": as vicissitudes da nomenclatura e suas implicações regulatórias. Revista Brasileira de Ciências Sociais, v. 23, p. 109-124, 2008.

36. MOL, A. Política ontológica. Algumas ideias e várias perguntas. In: NUNES, João Arriscado; ROQUE, Ricardo (Orgs.). Objectos impuros. Experiências em estudos sociais da ciência. Porto: Edições Afrontamento, 2007.

37. MONTEIRO, M. Os dilemas do humano: reinventando o corpo numa era (bio) tecnólogica. São Paulo: Annablume/FAPESP, 2012.

38. PINTO, L. O. Resgatando afetos: um estudo antropológico sobre redes urbanas de proteção animal. 2016. Dissertação (Mestrado em Antropologia Social) ) Instituto de Filosofia e Ciências Humanas, Universidade Federal do Rio Grande do Sul, Porto Alegre, 2016.

39. PIRES, Marco Túlio. Quase humanos. Veja. 16 jul. 2012. Disponível em: http:// veja.abril.com.br/noticia/ciencia/quase-humanos. Acesso em: 12 jul. 2017. 
40. ROHDEN, F. O que se vê no cérebro: a pequena diferença entre os sexos ou a grande diferença entre os gêneros. In: MALUF, S.; TORNQUIST, C. S. (Orgs.). Gênero, saúde e aflição: abordagens antropológicas. Florianópolis: Letras contemporâneas, 2010.

41. ROHDEN, F. Prescrições de gênero via autoajuda científica: manual para usar a natureza? In: FONSECA, C.; ROHDEN, F.; MACHADO, P. S. (Orgs.). Ciências na vida: antropologia da ciência em perspectiva. São Paulo: Terceiro Nome, 2012-

42. SCHUCH, P. A moral em questão: a conformação de um debate em antropologia. In: WERNECK, Alexandre; CARDOSO DE OLIVEIRA, Luis Roberto. Pensando bem: estudos de sociologia e antropologia da moral. Rio de Janeiro: Casa da Palavra, 2014.

43. SEGATA, J. Os cães com depressão e seus humanos de estimação. Anuário Antropológico 2011, Brasília, v. 2, p. 1777-204, 2012.

44. SINGER, P. Libertação animal. Canoas: Lugano, 2008.

45. SORDI, C. O animal como próximo: por uma antropologia dos movimentos de defesa dos direitos animais. Cadernos IHU Ideias, São Leopoldo, v. 145, p. 3-28, 2011.

46. STRATHERN, M. Displacing knowledge: technology and the consequences for kinship. In: GINSBURG, F.; RAPP, R. (Orgs.). Conceiving the new world: the global politics of reproduction. Berkeley: University of California Press, 1995.

47. TONIOL, R. Espiritualidade que faz bem. Pesquisas, políticas públicas e práticas clínicas pela promoção da espiritualidade como saúde. Sociedad y Religión, v. XXV, p. 110-143, 2015.

48. WALKER, H. Values of happiness. Hau: Journal of Ethnographic Theory, v.5, n.3, p.1-23, 2015.

Recebido em 18 de fevereiro de 2019

Avaliador A: 26 de março de 2019

Avaliador B: 28 de fevereiro de 2019

Aceito em 29 de março de 2018 